\title{
Investigating an Integrated Solar Combined Cycle Power Plant
}

\author{
A Rashad ${ }^{1 *}$, A Elweteedy ${ }^{1}$ A Temraz ${ }^{2}$ and A Gomaa ${ }^{1}$ \\ ${ }^{1}$ Military Technical College, Egypt \\ ${ }^{2}$ Ph.D Candidate, Mechanical Engineering Department, Technical University of Darmstadt, Germany
}

*Corresponding author: A Rashad, Faculty of Mechanical Engineering, Military

Technical College, Egypt.

\begin{abstract}
Using solar energy standalone to generate electricity has high investment risk. This is due to the need to energy storage systems to ensure electricity generation during the night. For this reason the hybridization of renewable energy resources and fossil fuel has been motivated. In an Integrated solar combined-cycle (ISCC) the solar thermal energy is integrated into combined cycle gas turbine (CCGT) power plant. The aim of this study is to evaluate the impact of addition of solar energy to a CCGT at both design and off design conditions of solar thermal input and ambient temperature.

The evaluation was fulfilled by studying the main performance indicators for hybridization of combined cycle (CC) with solar energy. These factors are the solar conversion efficiency, solar fraction, and boosting factor.

The study was implemented on Kurymat ISCC, in Egypt. The plant is designed to produce $135 \mathrm{MWe}$. It composed of parabolic trough solar field integrated with a conventional CCGT power Plant. The design solar heat input is $50 \mathrm{MWth}$ at $20^{\circ} \mathrm{C}$ dry bulb ambient temperature. The CCGT consists of one gas turbines of $70 \mathrm{MWe}$, one HRSG that produce steam at pressure $90 \mathrm{bar}$ and a steam turbine of $65 \mathrm{MWe}$. The study shows that, for night mode operation (no solar) changing the ambient temperature from $50 \mathrm{C}$ to $35^{\circ} \mathrm{C}$, the plant efficiency drops from 0.53 to 0.51 and the output power changes from 119.2 MW to $99.69 \mathrm{MW}$. Also, for day mode (with solar) at design solar thermal input and ambient temperature the ISCC efficiency is higher than CC efficiency when we neglect the solar fuel cost, while the efficiency drops below that of the CC if the solar fuel cost is considered. The power output reduces with increasing the ambient temperature and increases with increasing the solar thermal input.
\end{abstract}

Keywords: Parabolic trough; Integrated solar combined cycle; Thermodynamic analysis
Abbreviations
CCGT - combined cycle gas turbine
CST - Concentrated solar thermal
DSG - direct steam generation
HPEC - High pressure economizer
HPEV - High pressure evaporator
HPSH - High pressure super heater
HRSG - Heat recovery steam generator
HTF - Heat transfer fluid
ISCC - Integrated solar combined cycle
LCOE - Localized cost of energy
LEC - Levelized energy cost

MENA - Middle East North Africa

NGCC - Natural gas combined cycle 


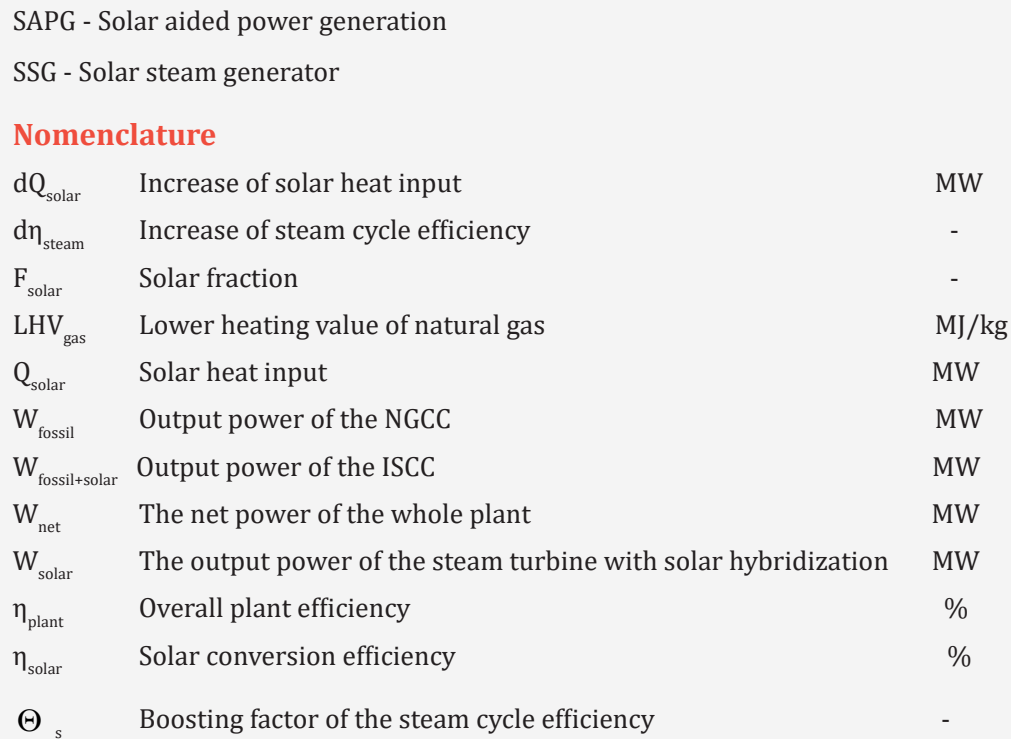

\section{Introduction}

Electricity generation from solar energy has been considered a feasible alternative for fossil thermal plant due to the fear of fossil fuel depletion. By using solar energy standalone to generate electricity, energy storage becomes a must to ensure electricity generation during the night. The systems of energy storage are characterized by high cost that causes a dramatic increase of the price of the generated electricity i.e, high investment risk [1]. For these reasons, the reliability of solar thermal power plant as a base load power source is not high. This problem caused searching new methods to reduce the power plant capital cost.

The willing of providing cost-effective improved and stiff electricity supply motivated the hybridization of renewable energy resources and fossil fuel in electricity production [2]. Also, the hybridization of fossil fuel and renewable energy is capable to achieve substantial economic and environmental benefits [3-6]. One method of hybridization of fossil fuel and renewable energy is to use a solar integration with fossil fuel power plant. This way fulfills effective use of solar and fossil resources, overcoming the problem of sunlight discontinuity. Moreover, it reduces the release of greenhouse gas. Also, the elimination of the thermal storage system reduces the plant cost [7-10].

Elmohlawy et al [2], Abdel Dayem et al [5] studied the impact of integrating solar energy into $\mathrm{CC}$ on the $\mathrm{CO}_{2}$ emission. Elmohlawyet al [2] developed a Mathcad mathematical model to simulate a proposed ISCC power plant with parabolic trough collectors under Egypt climate condition. In the first configuration the solar steam generator (SSG) is used to evaporate and superheat part of the feed water of the intermediate pressure economizer. In the second configuration the SSG is used to superheat the feed water extracted

from the deaerator. The results revealed that the second configuration results in more increase in net output power than the first one. Also, the second configuration generates more solar electricity than the first one. The solar integration reduced the $\mathrm{CO}_{2}$ emission by 51670.82 ton/year. Abdel Dayem [5] simulated a proposed integrated solar combined cycle power plant under north Benghazy/Lybia climate conditions. The study was implemented on two modes of operation: first; fuel saving mode where the solar steam is utilized to preheat the air before entering the gas turbine combustion chamber, second; power boosting mode where the solar steam is injected in the steam turbine. The results illustrated that the fuel saving mode reduced the $\mathrm{CO}_{2}$ emission by 7972.25 ton/year and the benefit/cost ratio is 1.74 /year.

Nathan et al [3], and Bahroon et al [6] examined the economic impact of solar energy integration into combined cycle. Nathan et al [3] made a review in order to: first; pinpoint the gain of concentrated solar thermal (CST) energy hybridization and combustion technologies. Second; pinpoint and categorize how CST and combustion can be merged in a hybrid system. Third; pinpoint the promising hybridization technologies for carbon-neutral or carbon-negative emission. Finally; pinpoint the challenges that face the development of such technologies. They observed that there are two classes of concentrated solar thermal hybrids. The first one is employed to preheat the feedwater to a regenerative Rankine cycle which is named Solar Aided Power Generation (SAPG). This category has 3-5\% annual solar share and it is limited to certain sites. The second one is hybrid solar receiver-combustor. By this technology the Localized Cost of Energy (LCOE) can be reduced up to 17\% and get a saving in fuel consumption to $40 \%$. Bahroon et al [6] developed a model to predict the beam radiation, the annual fuel consumption, 
the fuel cost, and the LCOE for an ISCC in Yemen working with coal and heavy oil. It was found that that the LCOE was higher when using heavy fuel oil than in case of coal.

AE Elmohlawy, et al. [7] elaborated two thermodynamic models to assess the performance of a two configurations of integrated solar combined cycle power plants with parabolic trough solar collector. In one configuration, the steam generated by the solar collector is injected into the high-pressure section while in the second configuration it was injected into the intermediate pressure section. The plants were proposed to operate under climate of southern Egypt. The results showed that the first configuration experienced higher increase in the output electrical power, net thermal efficiency, and solar to electric conversion efficiency than the second configuration.

A Rovira et al. [8] proposed a new configuration of ISCC includes a gas turbine with partial recuperation. The generated solar steam is injected into the high-pressure section of the evaporator. Partial recuperation reduces fuel consumption without changing the gas turbine operating conditions and hence, without decreasing its efficiency. The proposed new configuration of the ISCC was investigated in detail with two case studies: Las Vegas and Almeria; have been compared. Improvement of the minimum yearly heat rate of $1 \%$ and $1.8 \%$ in Almeria and Las Vegas respectively was observed. Concerning the cost analysis, the ISCC with partial recuperation achieved a lower LCOE by $0.9 \%$ and $1.1 \%$ for Almeria and Las Vegas respectively.

AE Elmohlawy, et al. [11] developed a model in Mathcad to investigate the performance of two layouts of ISCC. In both layouts the reference combined cycle is a triple pressure conventional gas turbine cycle. In the first layout, a fraction of feedwater is extracted from the intermediate pressure economizer and is superheated in a solar steam generator, then is injected into the exit from the intermediate pressure turbine. In the second layout, portion of feedwater is taken out the deaerator where it is evaporated in a solar steam generator and then is injected into the high-pressure steam heater. The analysis was implemented for climate conditions for a site in Aswan city, Egypt. The results showed that the first layout had a solar to thermal electricity efficiency of $37.6 \%$ in summer and $11 \%$ in winter. Also, it has a $43 \mathrm{MW}$ increase in output power in ummer and $12 \mathrm{MW}$ in winter. On the other hand, the first layout has $37 \mathrm{MW}$ increase in output power in summer and $10 \mathrm{MW}$ increase in winter.

AO Binamer [12] developed a mathematical model to assess the performance of ISCC power plant. The plant was planned to be erected in Kuwait with a 60 MWe capacity parabolic trough solar collector. Engineering Equation Solver (EES) was used to develop the model. The model was used in a sensitivity analysis to study the effect of certain parameters such as solar heat input. The results showed that the plant efficiency could increase up to $100 \%$ more than the conventional one. Also, the output power is strong- ly affected by solar heat input. It is more beneficial to add thermal energy storage than increase the solar fraction from 0.2 to 0.3 . by integrating thermal solar the annual emission was cut down and the Annual fuel saving was grown. These benefits encourage the implementation of this type of plants in Kuwait.

Achour et al [13], Manente[14], A Boretti et al. [15], Y Liang et al. [16] studied the influence of integrating solar energy into combined cycle on the efficiency. Achour et al [13] developed a thermodynamic model to estimate the thermal performance of an ISCC in Algeria. The solar to electricity efficiency was found to be up to $14.4 \%$ while the overall plant efficiency was up to $60 \%$. Manente [14] developed a model to assess the integration of solar energy into CC with including new equipment or without changing the existing equipment. The results illustrated that the solar to electricity efficiency was found to be 24 to $29 \%$. Moreover, the thermal efficiency of the integrated cycle was lowered due to the drop-in gas turbine efficiency at reduced loads. A Boretti et al. [15] Developed a computational analysis for a simulated ISCC to be located in Trindad and Tobago. The proposed plant is supposed to have a parabolic trough as a solar collector without thermal energy storage. The purpose was to identify the benefits gained in fuel conversion efficiency. The results showed that an increase of about $2.58 \%$ in the fuel conversion efficiency could be obtained for 8 hours operating period of the solar field per day. The increase was about $3.16 \%$ for 4 hours operating period per day. Y Liang et al. [16] proposed an ISCC consists of super critical $\mathrm{CO}_{2}$-Brayton cycle and organic Rankine cycle as a CGS. An optimization study was implemented using a nonlinear programming mode. For this ISCC the results showed that, an increase in thermal efficiency up to $3.6 \%$ could be obtained.

Brodrick et al [17], Manente et al [18] studied the optimization of integration of solar energy into combined cycle. Brodrick et al [17] investigated many designs of ISCC to get better configuration with annual solar contribution than the published designs. In this optimization analysis a bi-objective Pareto Fronts was constructed. Manente et al [18] used model built by Thermoflex to investigate three technologies of solar integration: parabolic trough, Linear Fresnel, and solar tower for optimum integration. The results revealed that the best performance was achieved by utilizing moderate temperature concentrating solar collectors due to reduced heat transfer irreversibilities. In turn the solar radiation-to-electricity conversion efficiency was up to $30 \%$.

Previous literatures give valuable information into the advantages of the ISCC technology and the best configurations, but examination of solar integration into CC power plant based on data of real working plant is rare. The main objective of the current work is to investigate in detail the effect of solar integration into an existing CCGT. The goal is to obtain the best integration conditions of the thermal energy into the CCGT cycle, thus obtaining the best plant performance. This goal was achieved by a detailed thermodynamic analysis of the Kurymat ISCC. The physical plant descrip- 
tion, various parameters and design data are utilized to study the effect of solar hybridization into combined cycle under design and off-design operations for a range of metrological input parameters such as ambient temperature and solar thermal input. This work is organized as follows: The Kurymat ISCC Power Plant is described in detail in section 2 . The design data and various parameters of the plant at design and off-design conditions are shown. Performance evaluation for the plant in both day mode and night mode operation at design point and at off-design conditions is presented in section 3. Finally, the main performance indicators for hybridization of CC with solar energy which are the solar conversion efficiency, solar fraction, and boosting factor are investigated at different metrological conditions in section 4. A proposal for the calculation of the ISCC efficiency was also introduced.

\section{The Kurymat ISCC Power Plant}

Kurymat ISCC [19] is the first plant of this type erected in Kurymat $\left(29^{\circ} .27^{\circ} \mathrm{N}\right)$, Egypt and has been operated interruptedly since July 2011. The plant is one of the first three of its kind in the Middle East North Africa (MENA). The other plants are located in Algeria and Morocco. Figure 1 illustrates the schematic diagram of the Kurymat ISCC power plant.

The plant consists of two main subsystems; the solar field subsystem and the combined cycle subsystem. The solar island consists of parallel rows of single axis tracking trough. The trough axes are oriented to north-south and track the sun as it moves in the sky from east to west. In reference day mode situation of $700 \mathrm{~W} / \mathrm{m}^{2}$ direct normal irradiation at solar noon of 21 March and $20^{\circ} \mathrm{C}$ ambient temperature, the solar field has a thermal capacity of $50 \mathrm{MW}_{\mathrm{th}}$; this enables the ISCC to generate 135 MWe of gross electric power output. Without solar heat, the plant generates 115 MWe electric power output. The difference between the two modes of operation is 20 MWe. The solar field includes 40 loops and each loop has four SKAL-ET 150 parabolic trough collectors covering $130,800 \mathrm{~m}^{2}$. The HTF is Therminol VP-1from Solutia Inc. operates between $12^{\circ}$ to $400{ }^{\circ} \mathrm{C}$ with mass flow of $250 \mathrm{~kg} / \mathrm{s}$ at $100 \%$ load [20]. Hot HTF returning from the solar field at $393{ }^{\circ} \mathrm{C}$ at a pressure of 20 bars is pumped through the solar heat exchanger. The HTF leaves the solar heat exchanger at $293^{\circ} \mathrm{C}$ and is pumped back into the solar field. The design HTF temperature rise across the solar field is on the order of $100^{\circ} \mathrm{C}$.

The Combined Cycle is located outside of the power block in the North of the plant. It has one heavy-duty gas turbine GE type MS6001FA with a $70 \mathrm{MWe}$ at $20^{\circ} \mathrm{C}$ ambient temperature and one HRSG. The flue gas flow rate to the HRSG is about $206 \mathrm{~kg} / \mathrm{s}$ from the gas turbine at temperatures of about $600{ }^{\circ} \mathrm{C}$ at full load operation. The flue gas leaves the HRSG at about $100^{\circ} \mathrm{C}$. The steam turbine is of type Siemens SST 900 series single casing, horizontally split condensing type steam turbine with a generator. At rated conditions of the gas turbine and HRSG full load operation, solar heat input of 50 MWth and $20^{\circ} \mathrm{C}$ ambient dry bulb temperature the steam turbine generator output is about $65 \mathrm{MW}$. The design parameters of the Kurymat ISCC and its major components are summarized in Table 1 (Figures 2\&3).

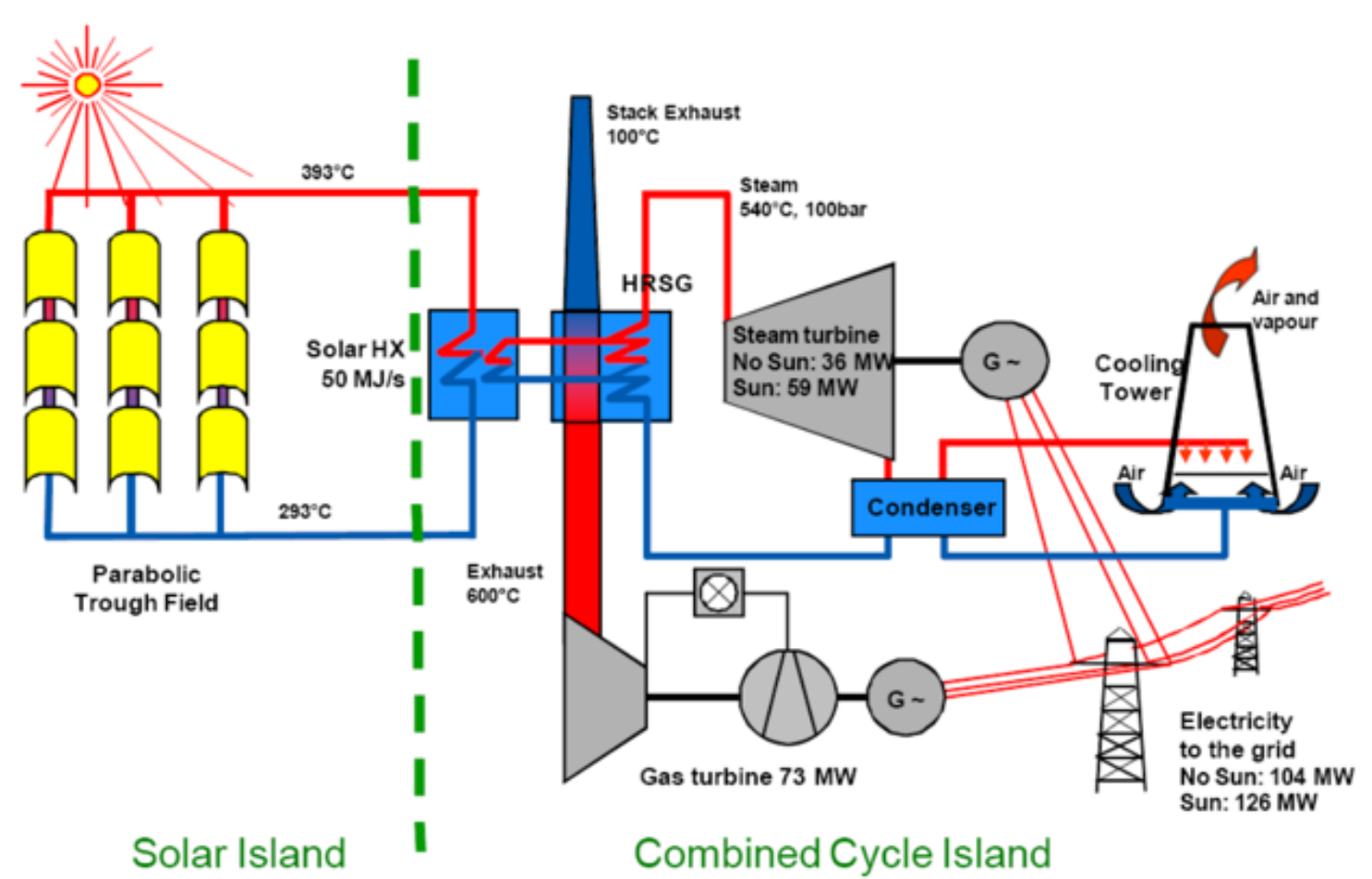

Figure 1: The schematic diagram of the Kurymat ISCC power plant. 


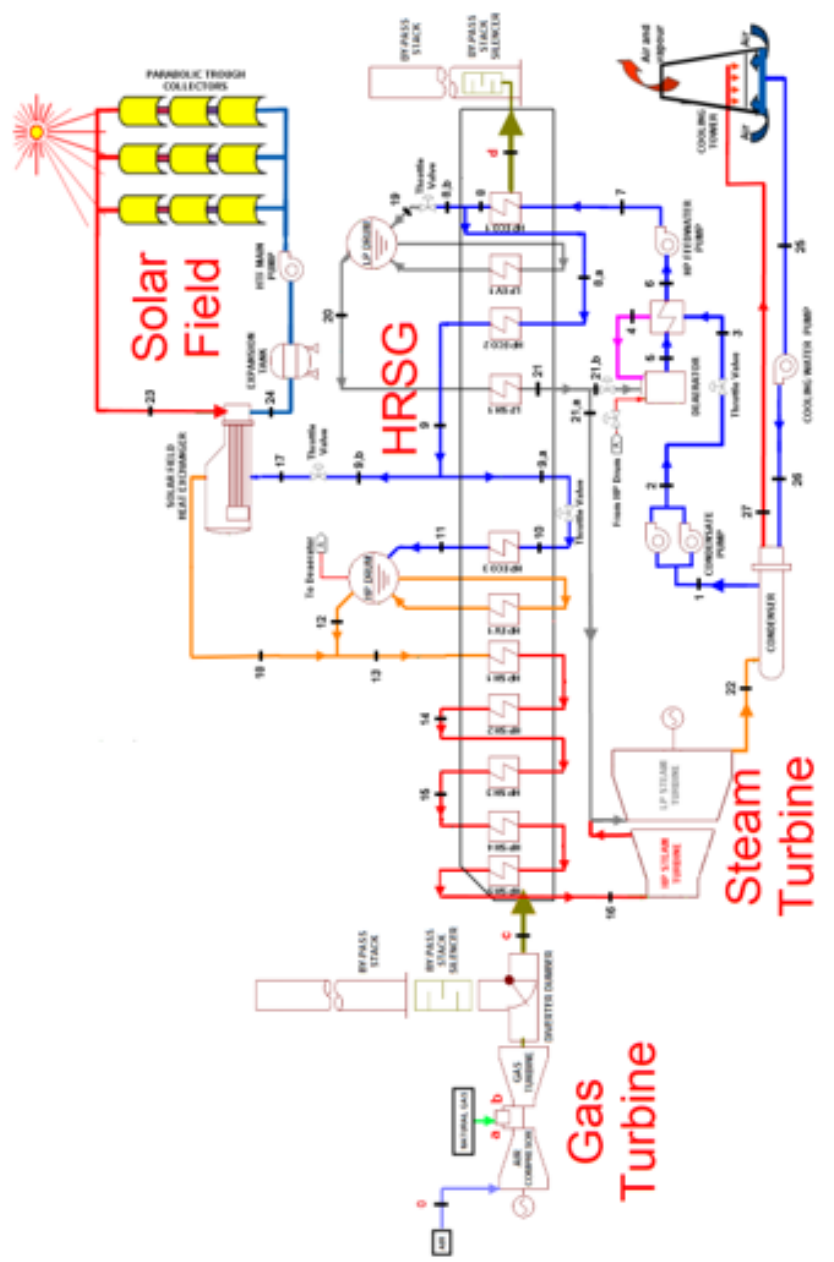

Figure 2: Schematic Diagram of ISCC in Kurymat, Egypt with state points illustration.

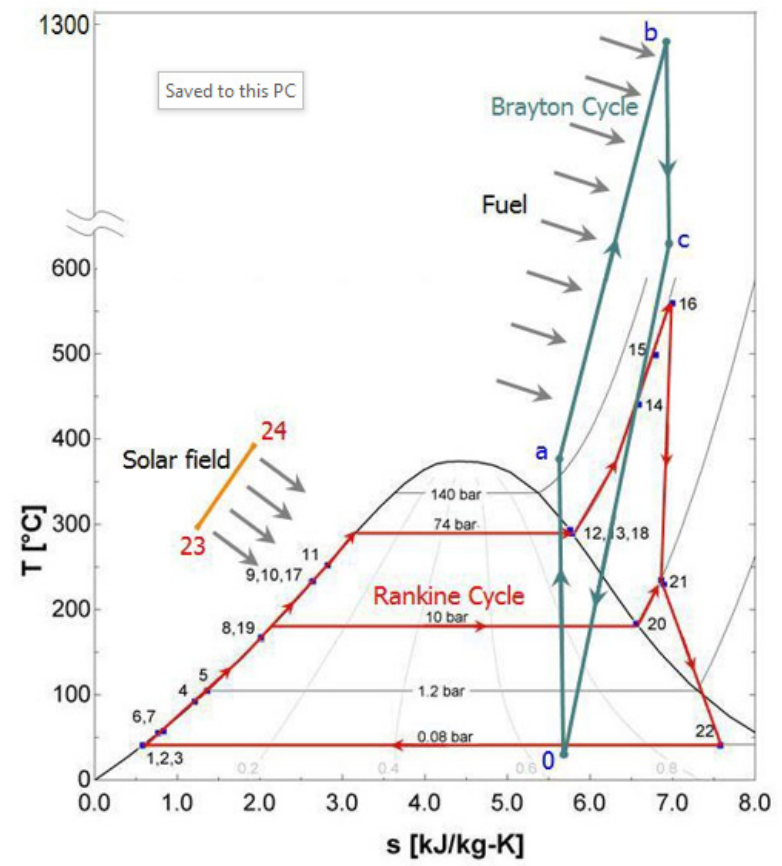

Figure 3: T-s diagram of ISCC in Kurymat, for $50 \mathrm{MW}$ solar heat input. 
Table 1: Kurymat power plan parameters at design point.

\begin{tabular}{|c|c|}
\hline Parameters & Values \\
\hline Design ambient pressure & $20^{\circ} \mathrm{C}$ \\
\hline Design ambient temperature & $63.30 \%$ \\
\hline Gross plant efficiency & $60.93 \%$ \\
\hline Net plant efficiency & 13.29 MWe \\
\hline Gross power & 129.251 MWe \\
\hline Net power & 1 \\
\hline No. of Gas turbine & $70 \mathrm{MWe}$ \\
\hline Gas turbine capacity & 1 \\
\hline No. of HRSG & 1 \\
\hline No. of Steam turbine & 65 \\
\hline Steam turbine capacity & 135 \\
\hline Total capacity & $605^{\circ} \mathrm{C}$ \\
\hline Flue gas inlet temperature & $90^{\circ} \mathrm{C}$ \\
\hline Flue gas outlet temperature & $206 \mathrm{~kg} / \mathrm{s}$ \\
\hline Flue gas mass flow rate & 50 MWth \\
\hline Design solar heat input & $48 \mathrm{~kg} / \mathrm{s}$ \\
\hline HP steam mass flow rate & $560{ }^{\circ} \mathrm{C}$ \\
\hline HP turbine inlet temperature & 69 bar \\
\hline HP turbine inlet pressure & $48 \mathrm{~kg} / \mathrm{s}$ \\
\hline LP steam mass flow rate & $560{ }^{\circ} \mathrm{C}$ \\
\hline LP turbine inlet temperature & 69 bar \\
\hline LP turbine inlet pressure & $31^{\circ} \mathrm{C}$ \\
\hline LP turbine outlet temperature & $0.05 \mathrm{bar}$ \\
\hline LP outlet pressure & 7 \\
\hline No. of HP exchangers & 2 \\
\hline No. of LP exchangers & $29 \mathrm{~kg} / \mathrm{s}$ \\
\hline \multicolumn{2}{|l|}{ Water mass flow rate to the HTF exchanger } \\
\hline Water inlet temperature to the HTF exchanger & $236^{\circ} \mathrm{C}$ \\
\hline Steam outlet temperature from the HTF exchanger $1.007 \mathrm{bar}$ & $394{ }^{\circ} \mathrm{C}$ \\
\hline
\end{tabular}

Table 2: Kurymat power plan state points at design conditions.

\begin{tabular}{|c|c|c|c|c|c|c|}
\hline Point & Fluid & Phase & $\dot{m}(\mathrm{~kg} / \mathrm{s})$ & P (bara) & $\mathrm{T}\left({ }^{\circ} \mathrm{C}\right)$ & $h(\mathrm{~kJ} / \mathrm{kg})$ \\
\hline 0 & Air & dead state & - & 1.007 & 20 & 294.465 \\
\hline $0^{\prime}$ & Water & dead state & - & & 20 & \\
\hline $0 "$ & Oil & dead state & - & & 20 & \\
\hline $\mathrm{a}$ & Air & & & & & \\
\hline $\mathrm{b}$ & Fluegases & & 206.36 & & & \\
\hline $\mathrm{c}$ & Fluegases & & 206.36 & 1.03 & 605.29 & 608.025 \\
\hline 1 & Water & sat. liquid & 49.92 & 0.05 & 31.07 & 130.2 \\
\hline 2 & Water & Comp liquid & 49.92 & 10.84 & 31.29 & 132.14 \\
\hline 3 & Water & Liquid-vapor & 49.92 & 10.29 & 31.37 & 132.2 \\
\hline 4 & Water & Liquid-vapor & 49.92 & 10.29 & 83.2 & 348.27 \\
\hline 5 & water & liquid & 51.75 & 1.2 & 104.8 & 439.3 \\
\hline 6 & water & liquid & 51.75 & 1.2 & 55 & 230.33 \\
\hline 7 & water & liquid & 51.75 & 144.13 & 57.2 & 251.6 \\
\hline 8 & water & liquid & 51.75 & 147.5 & 168.1 & 718.65 \\
\hline
\end{tabular}




\begin{tabular}{|c|c|c|c|c|c|c|}
\hline $8, \mathrm{a}$ & water & liquid & 46.78 & 147.5 & 168.1 & 718.65 \\
\hline $8, \mathrm{~b}$ & water & liquid & 3.85 & 147.5 & 168.1 & 718.65 \\
\hline 9 & water & liquid & 46.78 & 146.8 & 235.2 & 1016.63 \\
\hline $9, \mathrm{a}$ & water & liquid & 18.17 & 146.8 & 235.2 & 1016.63 \\
\hline $9, \mathrm{~b}$ & water & liquid & 28.79 & 140.83 & 236.48 & 1022.61 \\
\hline 10 & water & liquid & 18.17 & 76.32 & 235.5 & 1016.63 \\
\hline 11 & water & liquid & 18.17 & 76.24 & 255.2 & 110.98 \\
\hline 12 & water & sat. vapor & 18.17 & 76.23 & 291.7 & 2764.09 \\
\hline 13 & water & superheated & 46.78 & 75 & 290.8 & 2763.48 \\
\hline 14 & water & superheated & 46.78 & 73.55 & 439.8 & 3257.05 \\
\hline 15 & water & superheated & 46.78 & 17.97 & 500.4 & 3409.88 \\
\hline 16 & water & superheated & 47.71 & 69.38 & 559.26 & 3554.23 \\
\hline 17 & water & liquid & 28.79 & 79.68 & 236.72 & 1022.61 \\
\hline 18 & water & superheated & 28.79 & 78.74 & 293.9 & 2758.94 \\
\hline 19 & water & liquid & 3.85 & 10.94 & 169.8 & 718.65 \\
\hline 20 & water & sat. vapor & 3.85 & 10.91 & 183.7 & 2780.48 \\
\hline 21 & water & superheated & 3.85 & 10.22 & 232.7 & 2903.01 \\
\hline $21, \mathrm{a}$ & water & superheated & 2.21 & 10.22 & 232.42 & 2902.99 \\
\hline $21, \mathrm{~b}$ & water & superheated & 1.83 & 10.29 & 232.99 & 2903.99 \\
\hline 22 & water & sat.liq.vap. & 49.82 & 0.05 & 31.07 & 2302.21 \\
\hline 23 & Oil & liquid & 205.09 & 17 & 393 & 782.24 \\
\hline 24 & Oil & liquid & 205.09 & 16.79 & 293 & 538.44 \\
\hline 25 & water & liquid & 3931.58 & 1.007 & 20.56 & 86.34 \\
\hline 26 & water & liquid & 3931.58 & 2.9 & 20.57 & 86.58 \\
\hline 27 & water & liquid & 4078.11 & 2.33 & 27.25 & 114.47 \\
\hline
\end{tabular}

show the schematic and T-s diagrams with state points at design conditions. In Figure 2, the extraction and the injection points of steam in HRSG is shown. The steam is extracted from the high-pressure economizer (HP EC2) to the solar field heat exchanger and is injected into the high superheater (HP SH1). The values and conditions at different state points in Figure 2 at design situation are tabulated in Table 2. The various parameters and data of the plant at design and off-design conditions are selected from manufacturer data base [21].

\section{Plant Performance Analysis}

Thermodynamic analysis of the Kurymat ISCC is presented in this section. The detailed physical plant description and various parameters and data of the plant mentioned above are utilized to assess the effect of solar hybridization into combined cycle under design and off-design operations for a range of metrological input parameters; for instance; ambient temperature and solar thermal input. This section includes: first, performance evaluation for the plant in both day mode and night mode operation at design point. Then, the performance evaluation is carried out at off-design conditions.

The first law efficiency of the ISCC as a whole is calculated from the energy balance as:

$$
\begin{gathered}
\eta_{I, \text { Cycle }}=\frac{\dot{W}_{\text {elec }, I S C C}}{\dot{Q}_{I S C C, \text { in }}} \\
\dot{W}_{\text {elec }, I S C C}=\dot{W}_{\text {elec }, G T}+\dot{W}_{\text {elec }, S T} \\
\dot{Q}_{I S C C, \text { in }}=\dot{Q}_{\text {fuel }}+\dot{Q}_{\text {inc }}
\end{gathered}
$$

Where;

$\dot{W}_{\text {elec,ISCC }}=$ the electric power output of the ISCC power plant $[\mathrm{kW}]$.

$\dot{W}_{\text {elec }, G T}=$ the electric power output of the gas turbine [kW].

$\dot{W}_{\text {elec,ST }}=$ the electric power output of the steam turbine [kW].

$\dot{Q}_{I S C C, \text { in }}=$ the rate of total heat addition to the ISCC power plant $[\mathrm{kW}]$. 
$\dot{Q}_{\text {fuel }}=$ the rate of heat addition to the ISCC from the combustion of the fuel $[\mathrm{kW}]$.

$\dot{Q}_{i n c}=$ the rate of heat addition to the ISCC from the solar field $[\mathrm{kW}]$.

For night mode the solar heat is zero and the combined cycle efficiency will be:

$$
\eta_{\text {plant }}=\frac{W_{\text {net }}}{\dot{m}_{\text {gas }} \times \dot{L} H V_{\text {gas }}}
$$

The plant efficiency is calculated in two ways. First, as mentioned in all literatures the solar thermal heat input is not taken into consideration as an energy input, where the overall plant efficiency is calculated based on fossil fuel consumption only:

$$
\eta_{\text {ISCC }(a)}=\frac{W_{\text {ele }}}{\dot{Q}_{\text {fuel }}}
$$

But it is thought that the evaluation of the overall plant efficiency by this way is not right, because the solar thermal input is not free energy, actually it costs a lot to acquire that energy, so it is thought that solar thermal input must be considered when evaluating the overall plant efficiency. So the second way of calculating the efficiency is:

$$
\eta_{\text {ISCC }(b)}=\frac{W_{\text {ele }}}{\dot{Q}_{\text {fuel }}+\dot{Q}_{\text {solar }}}
$$

\section{Plant performance at design condition}

Figure 4 and Figure 5 show the variation of plant efficiency and power output as a function of the ambient temperature for night mode (no solar input). Figure 4 depicts the dependence of the gas turbine efficiency on the ambient temperature. It shows that, when ambient temperature changes from $5{ }^{\circ} \mathrm{C}$ to $35^{\circ} \mathrm{C}$ the gas turbine efficiency drops from 0.361 to 0.337 and the combined cycle efficiency drops from 0.532 to 0.51 . In Figure 5, the gas turbine power output decreased from $81 \mathrm{MW}$ to 67 which is about $17 \%$.at the same temperature variation. The reduction in the output power when rising the ambient temperature is owing to the reduction in the air mass flow rate delivered into the compressor. Also, the combined cycle output power is reduced from $119.2 \mathrm{MW}$ at $5{ }^{\circ} \mathrm{C}$ to $99.69 \mathrm{MW}$ at $35^{\circ} \mathrm{C}$ (about $16 \%$ ).

Figure 6 and Figure 7 show the variation of plant efficiency and power output for day mode at design solar thermal input $50 \mathrm{MW}_{\mathrm{th}}$. Figure 6 illustrates that the thermal efficiency of the ISCC increases over the combined cycle efficiency using the equation (5), while it is decreased lower than the combined cycle efficiency using equation (6). At the design ambient temperature $20^{\circ} \mathrm{C}$, the overall plant efficiency is reduced from 0.529 to 0.511 at about $3.4 \%$.

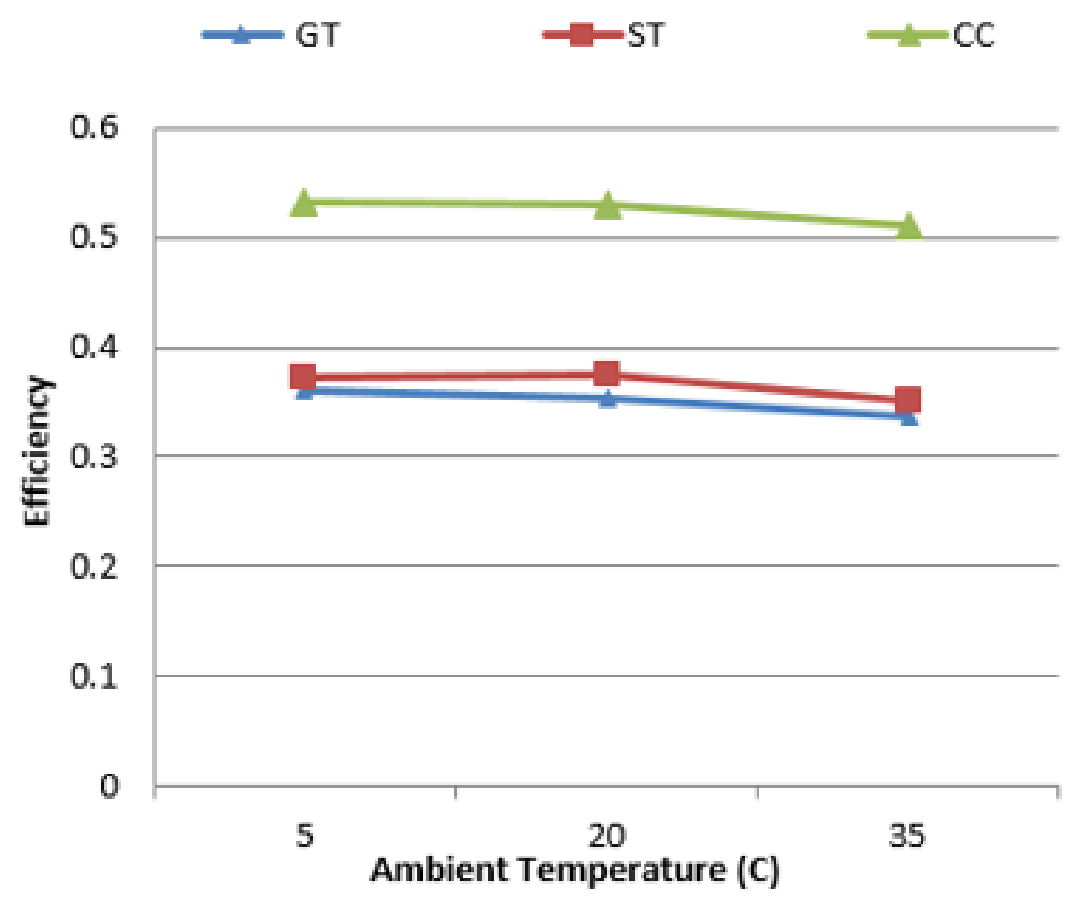

Figure 4: Variation of the Kurymat CC efficiency with the ambient temperature. 


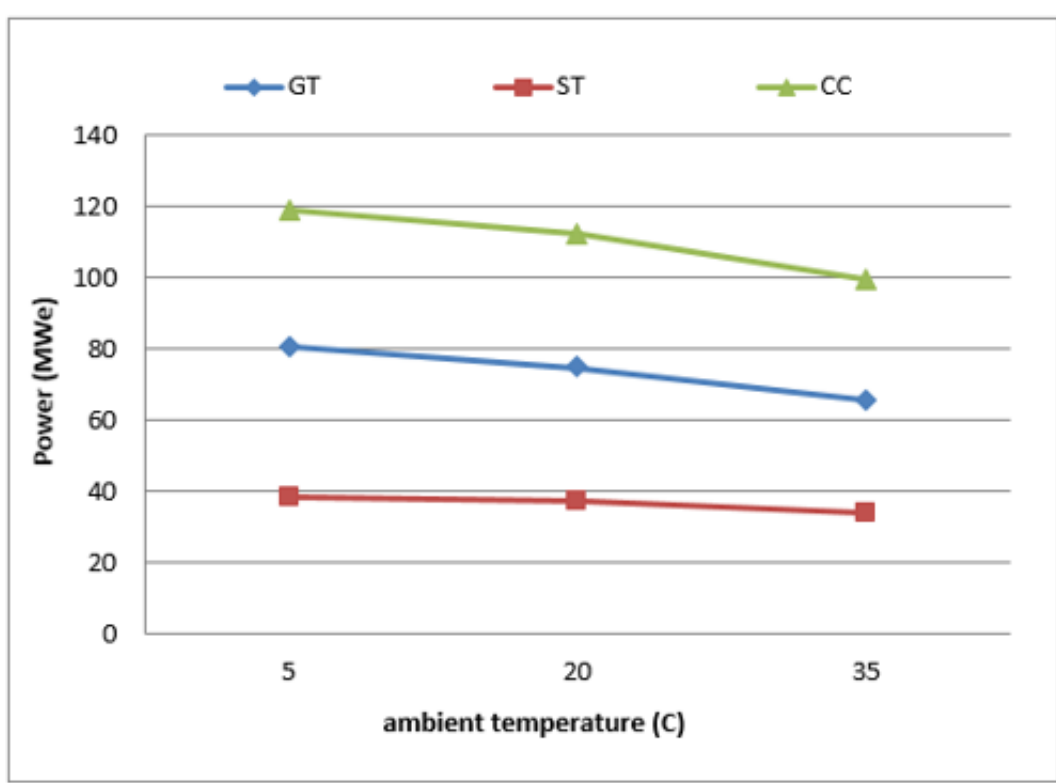

Figure 5: Variation of the Kurymat CC output power with the ambient temperature.

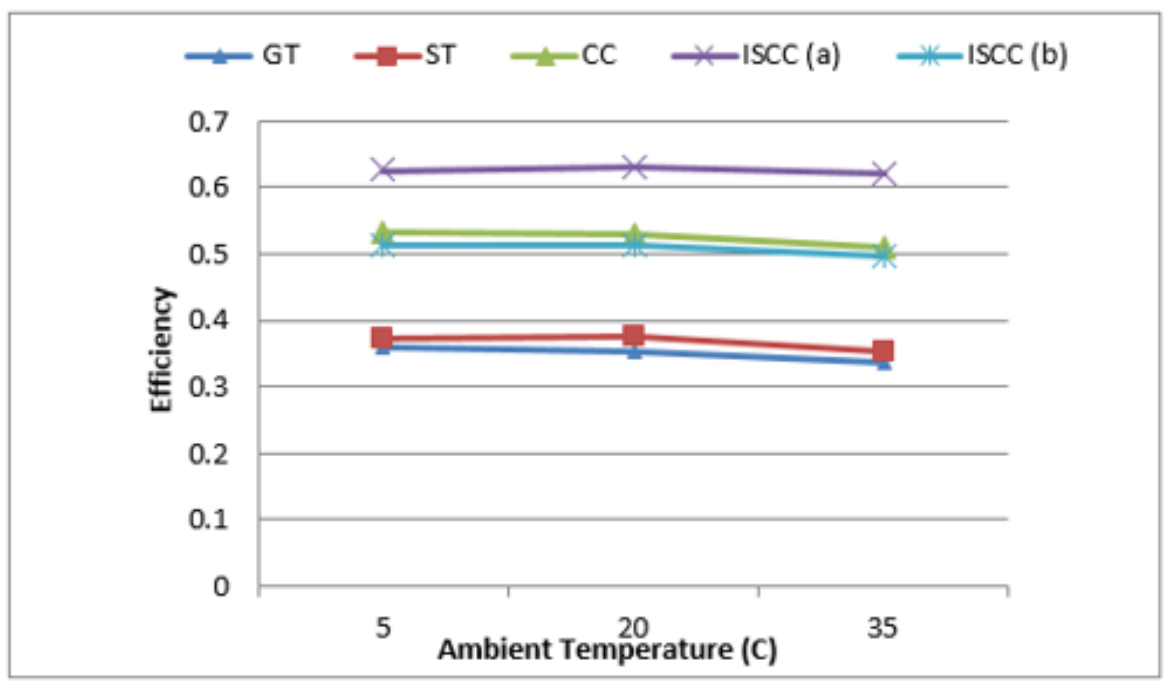

Figure 5: Variation of the Kurymat IS CC efficiency with the ambient temperature at design solar thermal input.

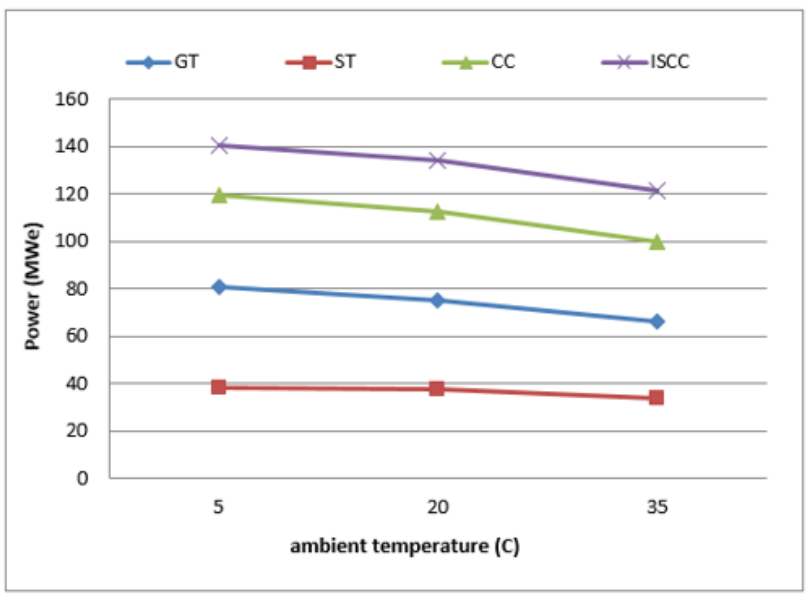

Figure 7: Variation of the Kurymat ISCC output power with the ambient temperature. 
Figure 7 illustrates the change of the output power along with the ambient temperature. It is clear that as a general trend, the output power decreases with increasing the ambient temperature. Also, the figure shows that at $20^{\circ} \mathrm{C}$ ambient temperature the ISCC power output is $134.3 \mathrm{MWe}$, while the CC power output is 112.45 MWe (about $19.4 \%$ increase).

\section{Plant performance at off-design conditions}

From subsection 3.1 at design point where the HRSG receives solar heat input of $50 \mathrm{MW}_{\text {th }}$ and the ambient temperature is $20^{\circ} \mathrm{C}$, the gas turbine output power is 70MWe and the steam turbine output is about 65MWe, while the thermal efficiency is 0.529 for night mode and 0.511 for day mode. In this subsection, the investigation for the off-design conditions is carried out for different solar heat input varied from $0,25,50,75,100 \mathrm{MW}_{\text {th }}$ respectively at different ambient temperature varied from $0,5,20,35^{\circ} \mathrm{C}$. The state point's conditions and values are obtained from manufacturer data base as mentioned above in section2. Appendix A shows as an example for state points data of ISCC in Kurymat at solar thermal input 100 MWth and $20^{\circ} \mathrm{C}$ ambient temperature. In this analysis, data from twenty combinations between solar thermal input and ambient temperature were used.
Figure 8 and Figure 9 illustrate the change of the overall plant efficiency with thermal heat input at different ambient temperature. In Figure 8, the efficiency is based on fossil fuel consumption only. It increases with increasing the solar heat input. The solar heat here is regarded as a complimentary heat source. Most of the literatures do that, i.e. they consider the solar heat input as a free energy source, but this consideration may cause ambiguous conclusion. The solar heat input is not free energy; it costs a lot to be collected, so it must be taken into consideration when calculating the overall plant efficiency. In Figure 9, when the overall plant efficiency is evaluated based on fossil fuel consumption and the solar heat gain, it was shown that the overall plant efficiency decreases with increasing the solar heat input. For example, at design ambient temperature $20^{\circ} \mathrm{C}$, the overall plant efficiency decreased from 0.52 at $25 \mathrm{MW}$ thermal heat gain to 0.485 at $100 \mathrm{MW}$ thermal heat gain. Both Figure 8 and Figure 9 show that the overall plant efficiency decreases with increasing the ambient temperature. Figure 10 shows the change of the overall plant power output with solar thermal heat input at different ambient temperature. It is clear that the power output reduces with increasing the ambient temperature and increases with the solar thermal input.

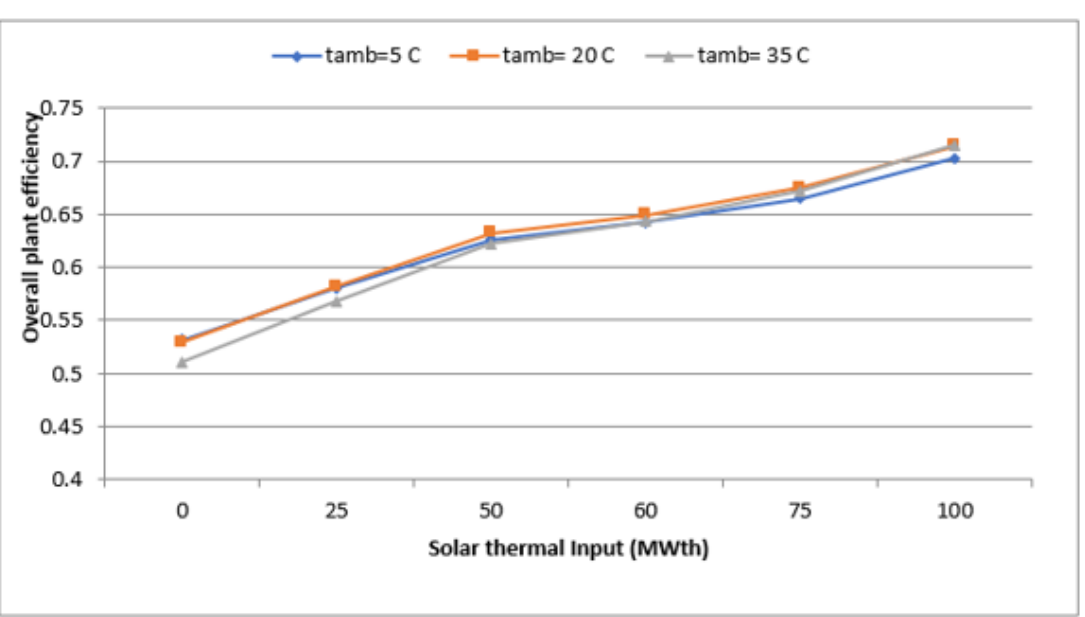

Figure 8: Overall plant efficiency as function of solar thermal input at different ambient temperature based on fossil fuel consumption only.

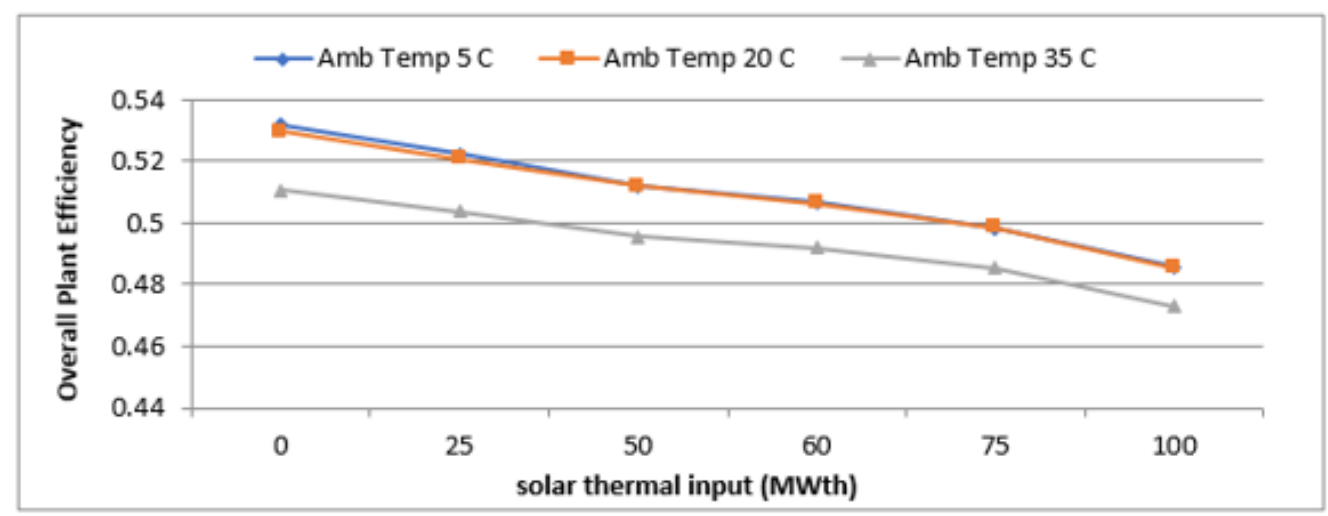

Figure 9: Overall plant efficiency as function of solar thermal input at different ambient temperature based on fossil and solar fuel consumption. 


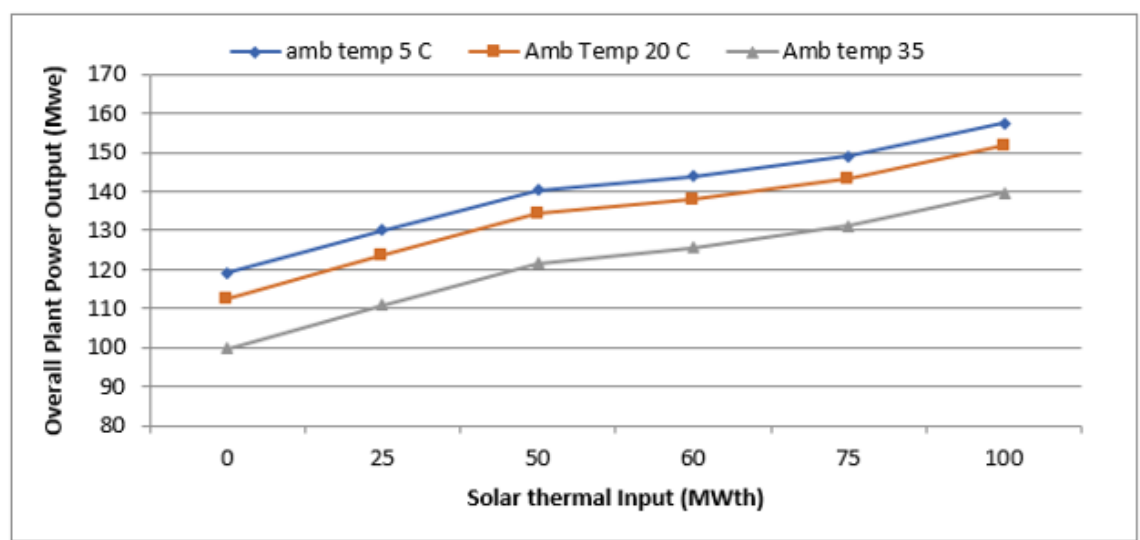

Figure 10: Variation of the overall plant power output with thermal heat input at different.

\section{Parametric Study}

The injection point of the solar heated steam is a critical parameter in the ISCC design, and a higher solar injection pressure/ temperature leads to higher solar conversion efficiency [9]. Also, it is preferable to maximize the solar fraction in the plant. The solar fraction relates the ratio of power generated from solar to the overall output power. Finally, the increase in the steam cycle efficiency can be characterized by boosting factor which denotes the increase in steam cycle efficiency per unit amount of solar heat added. We can say that, the solar conversion efficiency, solar fraction, and boosting factor are the main performance indicators in ISCC which mainly affected by injection point temperature/pressure. These performance criteria are defined as:

- Solar conversion efficiency:

$$
\eta_{\text {solar }}=\frac{W_{\text {solar }}}{Q_{\text {solar }}}=\frac{W_{\text {fossil }+ \text { solar }}-W_{\text {fossil }}}{Q_{\text {solar }}}
$$

- Solar fraction:

$$
F_{\text {solar }}=\frac{W_{\text {solar }}}{W_{\text {fossil }+ \text { solar }}}
$$

- Bossing factor of the steam cycle efficiency

$$
\Theta_{s}=\frac{d \eta_{\text {steam }}}{d Q_{\text {solar }}}
$$

In this section, parametric study for different solar thermal input at different ambient temperature is presented to study their effects on the injection point conditions and the performance indicators.

In Figure 11, the variation of steam pressure at injection point with heat input at different ambient temperature is illustrated. The steam pressure increases as the solar heat input increases, thus, the pressure of water/steam in all heat exchangers increases. This means the injection pressure and temperature of the HP evaporator (HP EV) increase.

Figure 12 shows the relation between steam temperature at injection point and heat input at different ambient temperature. The figure shows that the injection temperature increases from about $279{ }^{\circ} \mathrm{C}$ at $25 \mathrm{MW}$ to $315^{\circ} \mathrm{C}$ at $100 \mathrm{MW}$ solar heat input. It is noted that, the ambient temperature has no effect on the injection point conditions.

Figure 13 illustrates the change of the solar conversion efficiency and the steam cycle efficiency with the solar heat input. From the figure it is obvious that the solar conversion efficiency is higher than the steam cycle efficiency. The steam cycle efficiency increases with increasing the solar heat input and it has asymptotic manner. This is due to the increase in steam turbine output. Also, the figure reveals that the solar conversion efficiency reduces with increasing the solar heat input. Moreover, it is shown that the steam cycle efficiency decreases with increasing the ambient temperature, while the solar conversion efficiency increases with increasing the ambient temperature.

Figure 14 shows the variation of the steam cycle efficiency boosting factor with the solar heat input. Also, the figure relates the solar conversion efficiency and the boosting factor. It is obvious from the plot that both of them have the same trend which means that the solar conversion efficiency is driven by the boosting fact. Both of the solar conversion efficiency and the boost factor increase with increasing the ambient temperature and decreases with solar heat input. Figure 15 shows that the solar fraction increases with increasing the ambient temperature solar heat input.

\section{Conclusion}

In this work the response to various amounts of solar hybridization of Kurymat ISCC in Egypt was investigated from thermodynamic point of view. The investigation includes the evaluation of the off-design performance. It is carried out at different ambient temperatures and different solar heat input. The following can be concluded from this study: 


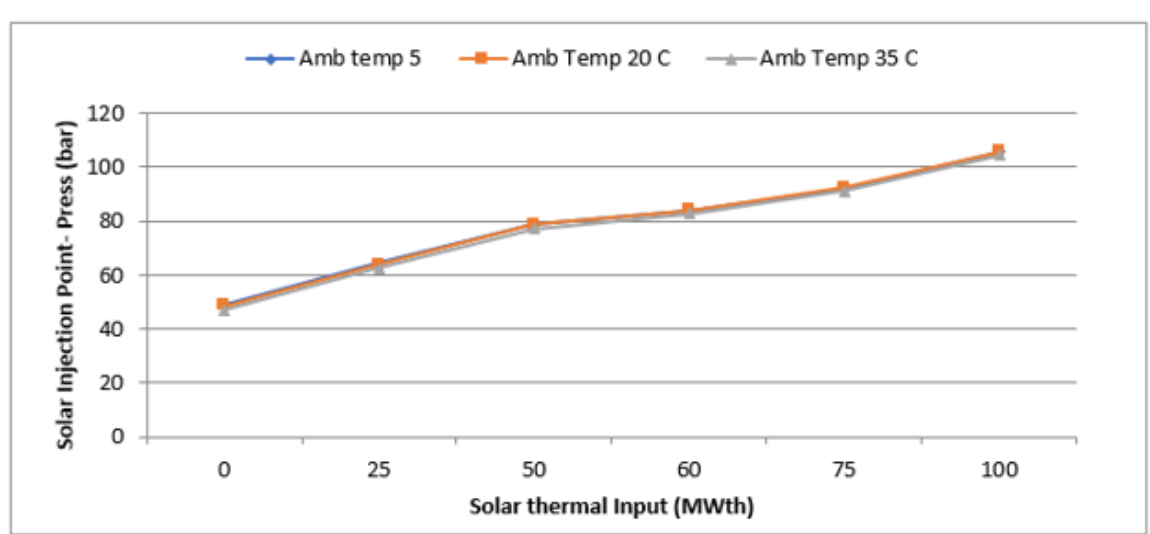

Figure 11: Variation of steam pressure at injection point with heat input at different ambient temperature.

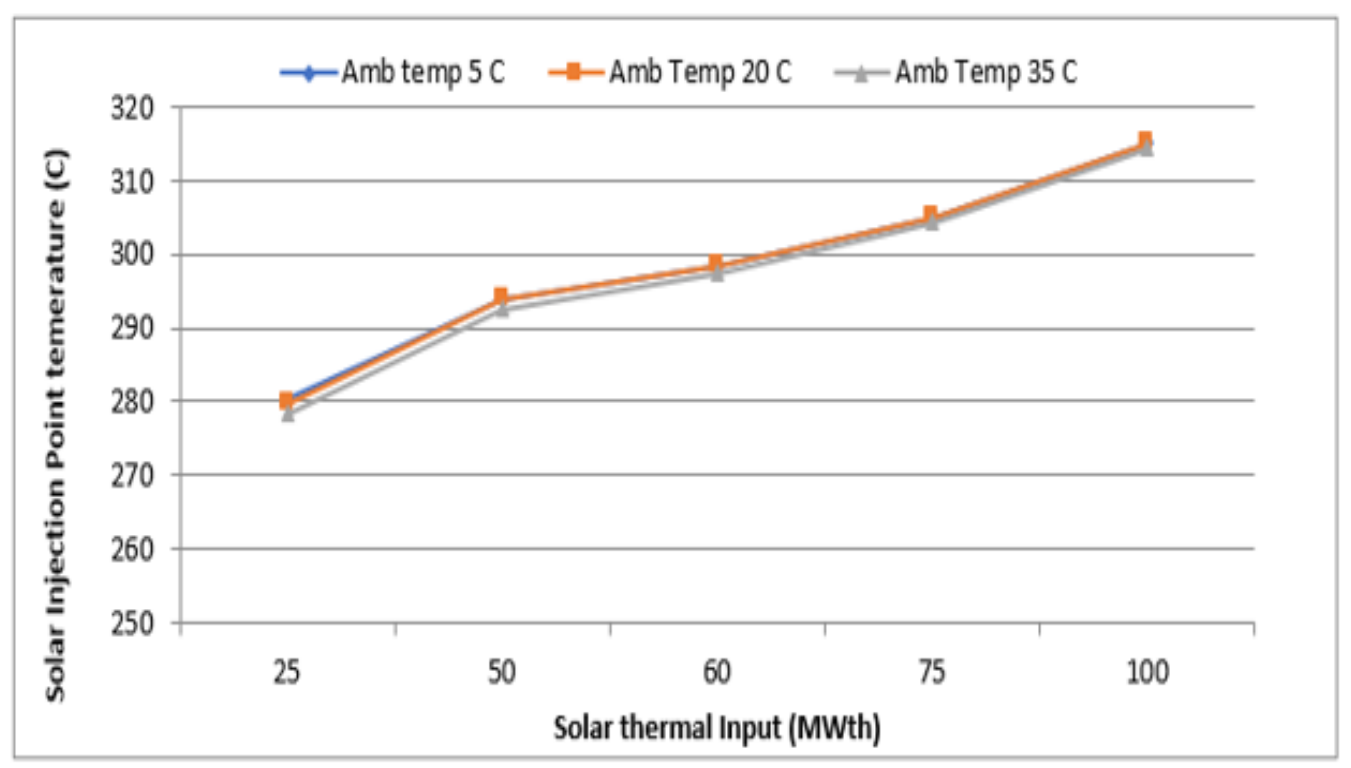

Figure 12: Variation of steam temperature at injection point with heat input at different ambient temperature.

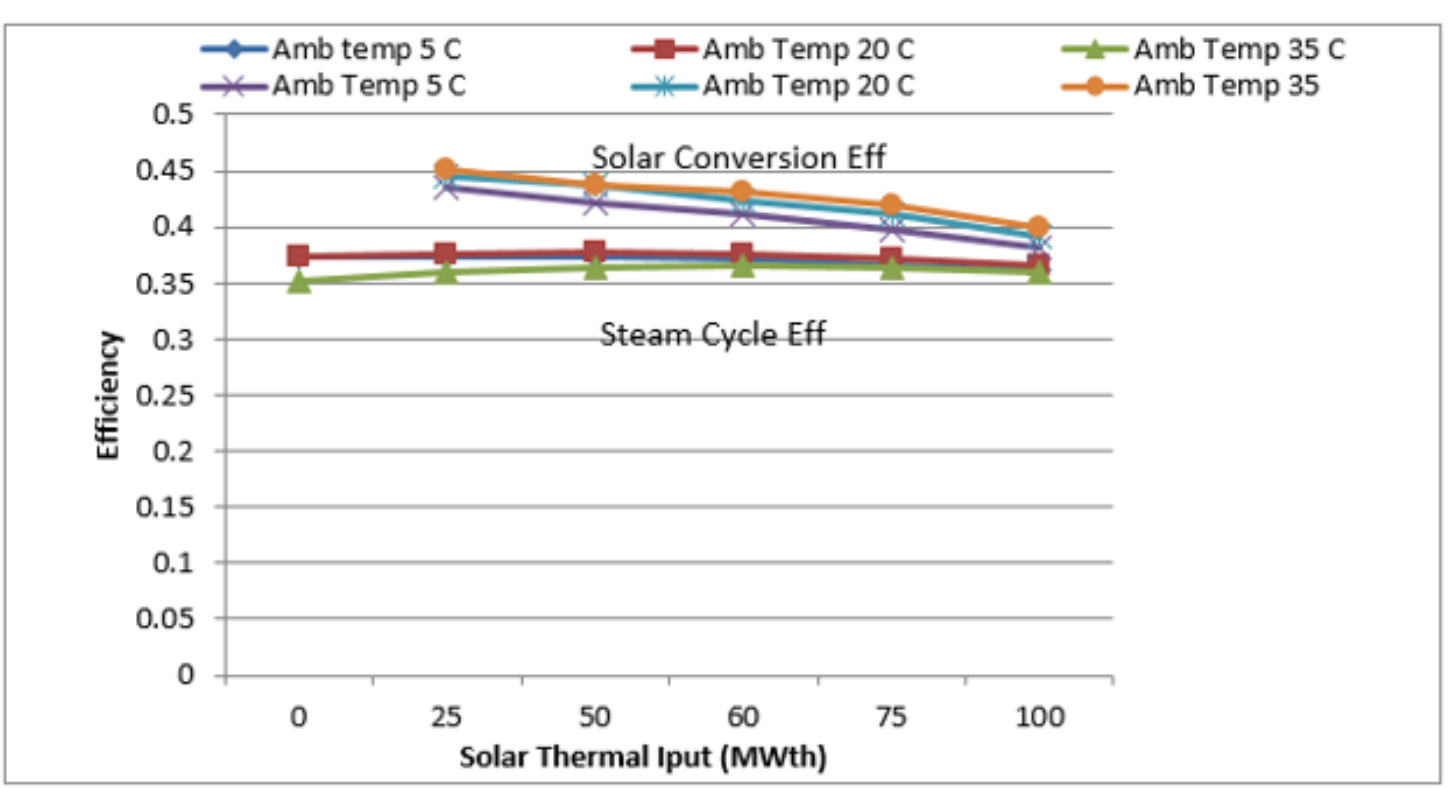

Figure 13: Comparison of solar conversion efficiency to steam cycle efficiency. 


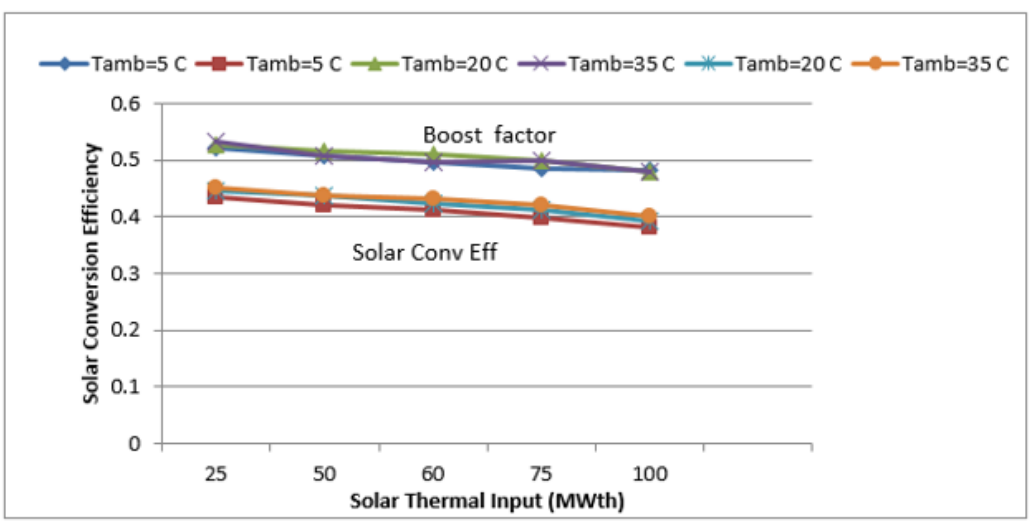

Figure 14: Comparison of solar conversion efficiency to steam cycle boosting factor.

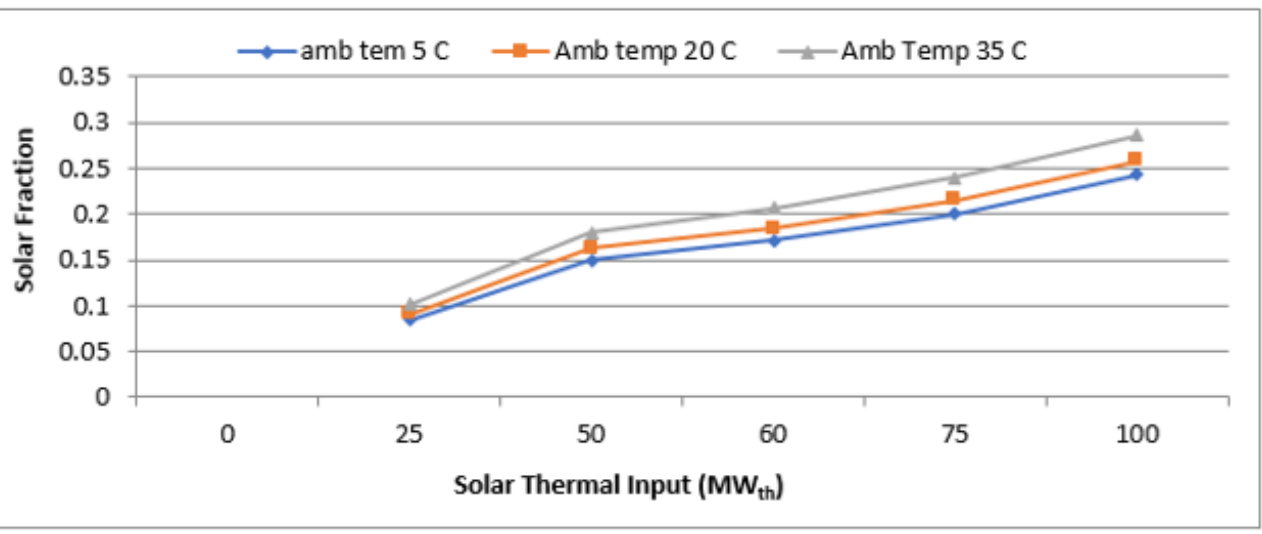

Figure 15: Variation of the solar fraction with solar heat input.

- The plant has solar conversion efficiency higher than steam cycle efficiency

- Utilizing solar power to substitute fractional heat of the HP EV in the HRSG may offer a considerable solar fraction up to about $26 \%$ which leads to saving of fossil-fuel and a consequent decrease in greenhouse-gas emissions.

- High pressure inlet steam temperature decrease with increasing solar heat input

- High pressure inlet steam pressure increase with increasing solar heat input

- Solar injection point temperature increase with increasing solar heat input

- Solar injection point pressure increases with increasing solar heat input

- Solar conversion efficiency decrease with increasing solar heat input

- Steam cycle efficiency increase with increasing solar heat input

- Boosting factor of the steam cycle efficiency decrease with increasing solar heat input
- Solar conversion efficiency decreases with increasing solar heat input

- Overall plant power output increase with increasing solar heat input

- Solar fraction increase with increasing solar heat input

- The effect of the ambient temperature is:

- Increasing the ambient temperature leads to decrease of gas turbine efficiency, gas turbine power output, solar injection point pressure, steam cycle efficiency, overall plant power output, and the solar fraction

- Increasing the ambient temperature leads to increase of high-pressure turbine inlet steam temperature, solar conversion efficiency, and the solar fraction.

- The overall plant efficiency is an important factor. In many literatures it was calculated after hybridization without taking into consideration the thermal heat input. It was claimed that it is a free energy [9]. Thus, the thermal efficiency is found to increase, but really the evaluation of the overall plant efficiency by this way is not right, because the solar thermal input is not free energy. Actually, it costs a lot to acquire that energy, so it is thought that solar thermal input must be taken into con- 
sideration when calculating the overall plant efficiency.

\section{Acknowledgement}

None.

\section{Conflict of Interest}

No conflict of interest.

\section{References}

1. MS Jamel, AA Rahman, AH Shamsuddin (2013) Advances in the integration of solar thermal energy with conventional and nonconventional power plants. Renew Sustain Energy Rev 20: 71-81.

2. AE Elmohlay, VF Ochkov, BI Kazandzhan (2019) Study and prediction the performance of an integrated solar combined cycle power plant. Energy Procedia 156: 72-78.

3. GJ Nathan, M Jafrian, BB Dally, WL Saw, PJ Ashman, et al. (2018) Solar thermal hybrids for combustion power plant: A growing opportunity. Progress in Energy and Combustion 64: 4-28.

4. L Duana, W Qubc, S Jiaa, T Fenga (2017) Study on the integration characteristics of a novel integrated solar combined cycle system. Energy 130: 351-364.

5. AM Abdel Dayem, M N.Metwally, AS Alghamdi, EM Marzouk (2014) Numerical simulation and experimental validation of integrated solar combined power plant. Energy Procedia 50: 290-305.

6. DA Bahroon, H Abdul Rahman (2014) Performance evaluation of solarfossil fuel-hybrid parabolic trough power plant in Yemen under different fuel types. proceeding of 2014 IEEE Conference on Energy Conversion (CENCON), pp. 158-163.

7. AE Elmohlawy, VF Ochko, BI Kazandzhan (2019) Thermal performance analysis of a concentrated solar power system (CSP) integrated with natural gas combined cycle (NGCC) power plant. Case Studies in Thermal Engineering 14: 100458 .

8. A Rovira, R Abbas, CS_anchez, M Munoz (2020) Proposal and analysis of an integrated solar combined cycle with partial recuperation. Energy 198: 117379

9. G Zhu, T Neises, C Turchi, R Bedilion (2015) Thermodynamic evaluation of solar integration into a natural gas combined cycle power plant. Renew Energy 74: 815-824.
10.E Pihl, F Johnsson (2012) Concentrated solar power hybrids technologies and european retrofit potential. Proceedings of ISES EuroSun 2012 conference, pp. 17-21.

11. AE Elmohlay, VF Ochkov, BI Kazandzhan (2019) Study and Analysis the Performance of Two Integrated Solar Combined Cycle. Energy Procedia 156: $72-78$.

12. AO Binmer (2019) Al-Abdaliya integrated solar combined cycle power plant: Case study of Kuwait, part I. Renewable Energy 131: 923-937.

13. L Achour, M Bouharkat, O Behar (2018) Performance assessment of an integrated solar combined cycle in the southern of Algeria. Energy Reports 4: 207-217.

14. G Manente (2016) High performance integrated solar combined cycles with minimum modifications to the combined cycle power plant design. Energy conversion and management 111: 186-197.

15. A Boretti, S Al-Zubaidy (2019) A case study on combined cycle power plant integrated with solar energy in Trinidad and Tobago. Sustainable Energy Technologies and Assessments 32: 100-110.

16. Y Liang, J Chen, X Luo, J Chen, Z Yang, Y Chen (2020) Simultaneous optimization of combined supercritical $\mathrm{CO}_{2}$ Brayton cycle and organic Rankine cycle integrated with concentrated solar power system. Journal of cleaner production 266: 121927.

17. PG Brodrick, AR Brandt, LJ Durlofsky (2018) Optimal design and peration of integrated solar combined cycles under emissions intensity constraints. Applied Energy 226: 979-990.

18. G Manente, S Rech, A Lazzaretto (2016) Optimum choice and placement of concentrating solar power technologies in integrated solar combined cycle systems. Renewable Energy 96: 172-189.

19. G Brakmann, FA Mohammad, M Dolejsi, M Wiemann (2009) Construction of the ISCC Kuraymat. Proceedings of International SolarPACES Conference, pp. 1-8.

20. THERMINOL VP-1 Heat Transfer Fluid Data Sheet, SOLUTIA Inc, 2010

21. ISCC Kuraymat heat balance list (2009) New \& Renewable Energy Authority (NREA), Egypt. 